University of Nebraska - Lincoln

DigitalCommons@University of Nebraska - Lincoln

\title{
Disrupting Cultural Selves: Constructing Gay and Lesbian Identities in Rural Locales
}

Emily Kazyak

University of Nebraska-Lincoln, ekazyak2@unl.edu

Kazyak, Emily, "Disrupting Cultural Selves: Constructing Gay and Lesbian Identities in Rural Locales" (2011). Sociology Department, Faculty Publications. 158.

https://digitalcommons.unl.edu/sociologyfacpub/158

This Article is brought to you for free and open access by the Sociology, Department of at DigitalCommons@University of Nebraska - Lincoln. It has been accepted for inclusion in Sociology Department, Faculty Publications by an authorized administrator of DigitalCommons@University of Nebraska - Lincoln. 


\title{
Disrupting Cultural Selves: Constructing Gay and Lesbian Identities in Rural Locales
}

\author{
Emily Kazyak \\ Department of Sociology \& Program in Women's and Gender Studies, \\ University of Nebraska-Lincoln, 725 Oldfather Hall, Lincoln, NE 68588, USA \\ email ekazyak2@unl.edu
}

\begin{abstract}
Research points to the increasing geographical diversity of gays and lesbians, in contrast to cultural narratives that link gay and lesbian sexualities to urban spaces. Examining the sexual identity constructions of rural gays and lesbians thus provides an opportunity to analyze the connection between cultural and personal levels of narrative identity. Drawing on data from thirty interviews with rural gays and lesbians, I address how this group negotiates cultural narratives about queerness and constructs sexual identities in rural locales. I find that their interpretations of geography make clear distinctions between urban/rural and draw on elements in rural culture. These interpretations provide resources to modify cultural understandings that narrate gay/lesbian identities in rural areas as closeted, hidden, and oppressed.
\end{abstract}

Keywords: gay, lesbian, geography, rural, identity

Cultural narratives and popular representations of gay and lesbian sexualities are embedded in a particular geographic story. Namely, that the rural and the Midwest are spaces where gay and lesbian sexualities are unclaimed, stunted, or destroyed and, in contrast, urban spaces are where those identities are constructed and made visible. People certainly have engaged in non-normative gender and sexual practices and have created queer social worlds in rural contexts (Fellows 1996; Howard 1999; Johnson 2007), but gay and lesbian identities have been entangled with urban spaces in both cultural and personal understandings (Abraham 2009; Weston 1995). However, research indicates an increasing geographical diversity and visibility of gay and lesbian couples in both non-urban locales and the Midwest (Black et al. 2000; Gates 2006, 2007; Rosenfeld and Kim 2005). Such evidence suggests a disruption in cultural narratives about what it means to be gay or lesbian - narratives that link those sexual identities to urban spaces. While we know that this might be happening, little is know about how it is happening. In other words, given the increasing geographical diversity of gay and lesbian couples, work needs to be done to understand if and how the relationship between geography and sexuality is shifting in how people construct gay and lesbian sexual identities. 
Drawing on data from thirty interviews, I provide an analysis of how rural gays and lesbians engage with and modify cultural narratives that link gay and lesbian identities and communities to cities. First, I ask how gays and lesbians in rural areas make sense of cultural narratives about gay and lesbian sexualities. I illustrate that they draw on their understandings of "rural" and "urban" to construct "urban gays" and "rural gays" as groups they describe as distinct. By making this distinction, rural gays and lesbians do not disavow "gay" or "lesbian" identity, but rather modify the assumed essential link between urbanism and gay identity in cultural narratives. I also demonstrate how they narrate nuanced understandings of rural, which provides a resource to modify the cultural narrative that scripts rural space and people inhabiting it as intolerant of gays and lesbians. Second, I ask how rural gays and lesbians construct sexual identities, focusing on their understandings about what it means to be out, visible, and accepted as gay or lesbian. I argue that the following understandings of rurality are central to how they narrate sexual identities: being known as a good person, having ties to the community, and the close-knit nature of rural life. As interviewees draw on interpretations of rural culture, they modify cultural understandings that narrate gay and lesbian identities in rural areas as closeted, hidden, and oppressed. Before turning to these findings and discussion, I outline the theoretical frameworks and the existing literature that ground this research and detail the research methods and data on which this paper is based.

\section{Personal \& Cultural Levels of Identity}

Scholars interested in identity have focused on the stories that people tell because it is in analyzing narratives that we can understand how people construct their identities and make sense of their experiences (Gergen 1994; Fine and Fields 2008; Somers 1994). Narratives also work at cultural and institutional levels in a number of ways. Through storytelling, collective identities and social movements are forged (Armstrong 2002; Bernstein 1997; Ghaziani 2008; Plummer 1995), and allies are created (Broad 2002). The narrative about geography and sexuality is one such narrative that constructs cultural understandings about gay and lesbian identities. Specifically, we might consider it an example of what Loseke (2001) calls a "formula story": a narrative that offers a template for a type of experience and involves distinct types of characters. This framework for understanding gay and lesbian sexualities reveals a circulating formula story about geography and the experience of being gay or lesbian. The story produces numerous cultural identities or "disembodied types of actors" (Loseke 2007, 663). At the heart of the narrative is the "stock character" the "oppressed rural gay": those who must flee to the city to come out, find a queer community, and become liberated. Another stock character that makes the formula story plausible includes the rural heterosexual who is homophobic (thus necessitating the need for gays and lesbians to flee).

Related to these stock characters, the formula story reflects "symbolic codes" or shared meanings surrounding geography. The story makes clear distinctions between rural and urban - where rural space is backwards and inhospitable to gays and lesbians and urban space is sophisticated and welcoming of gays and lesbians. Importantly though, symbolic codes are not universally understood in the same way (Holstein and Gubrium 2000; Loseke 2007). Given the variation in interpretations of urban and rural, it makes sense that those living in rural contexts, for instance, might have very different interpretations of rural than do those who have only lived in cities. Also, though there might be collective meanings circulating about what it means to be gay or lesbian-one, for instance, that posits an essential link between urbanism and 
non-normative sexual identity - people who adopt a gay identity will engage with that circulating meaning in different ways.

Indeed, while people use formula stories in making sense of their experiences, these stories are not determinative of personal identities (Holstein and Gubrium 2000). Scholars have called for the need to analyze how narratives might be modified in a migration between cultural and personal realms (Loseke 2007). Since gay and lesbian sexual identities are linked to urban spaces in cultural narratives (Halberstam 2005), analyzing the sexual identity constructions of rural gays and lesbians can illuminate the relationship between personal and cultural levels of narrative identity and how modifications might occur between them. Following other scholars who analyze formula stories, my claim is not that the story is inaccurate, but that it necessarily fails to capture the diversity of gays and lesbians' lived experiences (Crawley and Broad 2004; Loseke 2001). Applying the concepts of "stock characters" and "symbolic codes" to this study reveals how rural gays and lesbians' interpretations of rural-urban differences and of rurality provide them with resources to modify cultural narratives that deny the possibility of being gay in the country. While the formula story equates rural with backwardness and hostility, rural gays and lesbians narrate a nuanced understanding of rural, an understanding that often valorizes elements of rural culture. These interpretations of geography allow rural gays and lesbians to understand their identities in contrast to cultural narratives that posit a particular understanding of the country. Despite a nuanced understanding of rurality, rural gays and lesbians construct an "urban gay" stock character in their narratives. This finding suggests that while people integrate complexity to some degree in their narratives about who they are, they do so by denying that same nuance to others whom they see as unlike themselves.

\section{Geography \& Gay and Lesbian Sexualities}

Scholars have focused on the importance of urban space for sexual minorities to come out and find others, and have documented the existence of gay communities in U.S. urban locales such as New York City, San Francisco, Chicago, and Buffalo (Achilles 1967/1998; Boyd 2003; Chauncey 1994; D'Emilio 1983; Harry and DeVall 1978; Johnson 1993; Kennedy and Davis 1993; Levine 1979/1998; Leznoff and Westley 1956/1998; Newton 1972; Rubin 1998; Weston 1995). Some work has begun to unearth histories of non-normative gender and sexual practices and communities in rural areas that are erased by the metropolitan focus in sexuality studies (Howard 1999; Johnson 2003, 2007). Johnson (2007) and Howard (1999) both illustrate how men in non-metropolitan areas create queer homosocial worlds that provide a space to express non-normative gender practices, same-sex desires and to find sexual partners. That the assumed link between city and queer practices and identities is not the entire story does not mean that it is inaccurate per se. For some, the urban/rural binary is embedded in the very way that they think about being gay insofar as urban space signifies the possibility to be gay or lesbian and find others, while rural space signifies oppression (Weston 1995). Weston argues that this thinking compelled numerous gays and lesbians to migrate to cities in the 1970s and 1980s during what she calls the "great gay migration."

Of course, not all people outside of metropolitan areas imagined the city in that way, as works like those of Johnson and Howard illustrate. Further, research indicates an increasing geographical diversity and visibility of gay and lesbian couples in non-urban locales (Black et al. 2000; Gates 2006, 2007; Rosenfeld and Kim 2005). Samesex couples' concentration in urban areas declined from 1990 to 2000 (Rosenfeld and Kim 2005). Seventeen percent of same-sex couples live in rural areas, and there was a 
fifty-one percent increase in same-sex couples in rural areas from 2000 to 2007 (Gates 2006). These patterns are attributed to gays and lesbians coming out in these areas, an increasing acceptance within their communities, and an increasing willingness to be counted in surveys. Such evidence suggests a disruption in cultural narratives about what it means to be gay or lesbian-narratives that link those sexual identities to urban spaces. The case of rural gay and lesbian identity construction can therefore shed light on how people engage with and modify cultural narratives.

Moreover, focusing on rural gays and lesbians extends analyses of "unmarked identities in marked spaces" (Brekhus 2003), namely gay and lesbian identity and life outside of urban locales. Although relatively small, increasing attention has been paid to gays and lesbians in rural areas and the findings presented in this article build on this literature. This research echoes some of the previous research findings while also contributing new understandings about the numerous ways that rural gays and lesbians construct sexual identities. One available framework for understanding these sexualities posits that different logics operate in rural areas, such that having sex with a samesex partner would not entail adoption of a gay or lesbian identity (Halberstam 2005; Howard 1999). Alternatively, research focusing on rural areas in the U.S. and the U.K. finds that people do construct gay and lesbian identities, but do so within an isolating and intolerant context. Such work identifies the elements rural gays and lesbians enjoy about rural life, including a slower pace, a connection to the outdoors, and close relationships with family and friends, yet also notes barriers they face with regard to their sexuality, including isolation, being closeted, and a lack of a visible gay community (Boulden 2001; Coby and Welch 1997; Kirkey and Forsyth 2001; McCarthy 2000; Oswald and Culton 2003). Similarly, when gays and lesbians who migrated out of rural areas return, they experience discomfort and feel closeted or invisible (Oswald 2002). This research suggests that "rural" and "gay" are incompatible, and that rural gays and lesbians might understand other facets of their identity (e.g. "rural") to be more important than their sexuality insofar as they are willing to tolerate living in areas where they cannot be out because they like many aspects of rural life. This research highlights characteristics of rural life that hinder constructions of gay and lesbian identities.

Yet, in his study of men in the South, John Howard $(1999,124)$ stresses the importance of "queer agency." He argues that focusing on dimensions of social isolation or religious conservatism, while relevant, hinders the ability to see how people create networks for queer practices and lives. Indeed, there were movements in the 1970s to create rural queer social worlds, where the rural was imagined as an escape from the urban in radical faerie and lesbian land movements (Bell 2000; Hennen 2008; Herring 2007). Such "back-to-the-land" lesbians populate the small town in Oregon that was the focus of Arlene Stein's (2001) ethnography. Stein cites the split between these lesbian "newcomers" and the locals as one component of why a ballot measure denying civil rights protections to gays won across rural Oregon. In her ethnography of rural queer youth, Gray (2009) also finds that ties to familiarity are central in influencing queer political activism in small towns. Gray analyzes how the importance of being a local as well as the "infrastructural poverty" of rural areas shape how rural queer youth negotiate demands to be out and visible. Negotiating the tension between asserting queer difference and claiming status as a local, some of the routes to visibility for sexual minority youth in rural areas include drag shows, gay pride picnics, or queer punk bands (Gray 2007).

Unlike the rural lesbians in Stein's study, the men and women I interviewed were, by and large, not newcomers, but people with long ties to the areas in which they lived. Thus, interviewees did not express surprise at how the locals lived, but rather, as locals, their interpretations of rural culture informed how they made sense of their 
gay and lesbian identities. Like Howard's work, my research documents how characteristics of rural life (as understood by people living there) produce rather than hinder constructions of gay and lesbian identities. Rather than privilege their rural identity over gay identity, this work illustrates how rural gays and lesbians modify cultural meanings about gay and lesbian sexualities. Rather than tolerate a hostile environment and remain closeted to enjoy small town life, the people I interviewed drew on their attachments to small town life to construct gay and lesbian identities. In this way, the people I interviewed, unlike Gray's participants, did not necessarily see a tension between claiming status as a local and claiming gay identities. In fact, they linked being a local to their understandings of why their sexualities are accepted. Their understandings of gay and lesbian identity and how they narrated what it means to be out and visible differ from the accounts of rural youth Gray studied. Many of the people I interviewed would understand activities like participating in activism, pride groups, or doing drag as connected to an urban-based gay identity. These differences underscore that there are numerous ways that gays and lesbians stay put and construct sexualities in rural areas.

\section{Data Collection and Analysis}

The data analyzed in this article come from 30 in-depth, semi-structured interviews that I conducted with gays and lesbians who were currently living in rural areas in the Midwest. These data are part of a larger project that examines the co-constructions of space, sexuality, class, and gender among gays and lesbians. The larger data set includes an additional 30 interviews with gays and lesbians who had grown up in rural areas and were currently living in urban locales. My decision to interview these groups reflects my assumption that the link between gay sexuality and urbanism is not inaccurate per se, but rather denies the diversity of lived experiences. Elsewhere I analyze the differences between the narratives of those currently living in rural areas and those currently living in urban areas (Kazyak 2010). In this article I am primarily concerned with how gays and lesbians living in rural locales - people seemingly outside of the cultural narrative that link urbanism and queerness - make sense of the formula story and how they construct sexual identities.

I recruited people who were currently living in rural Michigan and Illinois. My decision to recruit in Michigan and Illinois was driven by their similarities in regard to characteristics of gay and lesbian life and rural life. I recruited participants in both LGBT-specific and general venues. I placed a request for interviews in national and state-wide gay and lesbian publications, ${ }^{1}$ newsletters of LGBT state-wide organizations, ${ }^{2}$ and LGBT university list-servs. ${ }^{3}$ I also recruited participants by placing a request for interviews on Craigslist and through snowball sampling. The announcement asked for individuals who identify as "gay" or "lesbian" and who either are currently living or had grown up in a "small town, the country, or a rural area." Along with a description of these eligibility requirements, the announcement noted that participants would be compensated \$25 and that the interviews were confidential. The majority of participants (17) were recruited through publications, internet

1. These publications include Between the Lines, Lesbian Connection, and What Helen Heard.

2. I placed a request in a number of LGBT organizations' newsletters and websites, including chapters of Parents and Friends of Lesbians and Gays (PFLAG), Washtenaw Rainbow Action Project (WRAP), Out \& About Illinois, and Gay and Lesbian Association of Decatur Illinois.

3. These included: University of Michigan, Eastern Michigan University, Michigan State University, and Illinois State University. 
sites, and list-servs that were affiliated with gay and lesbian organizations. However, five individuals were recruited through Craigslist, a non-LGBT affiliated internet site. Eight people contacted me after hearing about the study from a friend or family member. That my recruitment materials specifically requested individuals who identified as gay or lesbian underscores a limitation of this research. Given this recruitment method, I did not interview individuals who may engage in sex with a same-sex partner without identifying as gay or lesbian. Thus, I am unable to address alternative ways that these experiences might be understood in rural areas.

I conducted all thirty interviews. Twenty were done in-person and ten were conducted over the phone. For the face-to-face interviews, I traveled to locations that were convenient for participants. ${ }^{4}$ Prior to starting the interview, I asked people to fill out a short demographic survey. The interviews were semi-structured and followed an interview schedule that covered questions about the area where they were living, experiences coming out as gay or lesbian, and experiences about being a lesbian or gay man in the area they were living. Since I was most interested in people's self-understandings, I often asked follow-up questions that were unique to individual interviews in order to get a better sense of how they made sense of themselves and their relations to others. ${ }^{5}$

Once the data were collected, I transcribed the interviews in full. I began analyses by reading through the transcripts and taking notes on what interesting themes were emerging. Following Emerson et al. (1995, 144), I approached analysis with a concern for generating and discovering new themes in the data while also recognizing that "data do not stand alone." Throughout the analysis process, I was concerned with pursuing "member's meanings" and asking questions about how individuals made sense of themselves, others, and their experiences (Emerson et al. 1995). Such concern made salient the distinctions that people saw between rural and urban people and their theories about why those existed. The themes that emerged from coding were developed into initial and integrative memos, which were then developed into the findings section below (Emerson et al. 1995). The integrative memos allowed me to analyze the relationship between what people described as important in rural areas and their narratives about sexuality. In order to ensure confidentiality, I have not used the actual names of towns or people. The quotes used have been edited for the sake of both confidentiality and clarity, but the meaning and words have not been otherwise changed.

\section{Profile of Participants}

Of the thirty people I interviewed, most had also grown up in a rural area; only six had not. The ages of the interviewees range from twenty-four to fifty-five. In terms of the gender and racial composition of the sample, it is comprised of more women and white interviewees. Of the three people who did not identify as white, they identified as Asian, Hispanic, and biracial. That nearly all participants identified as white is another limitation of this work, especially given that there has been an increase in immigrant and racial minority populations in rural areas in Midwestern states, including

4. The bulk of the in-person interviews took place in their homes, although I also met people at libraries, parks, and coffee shops.

5. That said, all interviewees were asked some variation on the following questions: Can you tell me a little about what your town is like? How did you come to be living here? (If they had lived in city, I also asked about experiences there). What do you like/dislike about living here? Do you feel similar to other people living here? Can you tell me a little about your coming out experience? Can you tell me a little about what it is like to be gay/lesbian living here? 
in Michigan and Illinois (Kandel and Cromartie 2004; Lichter and Johnson 2006). In this article I address how race is implicated in the degree to which interviewees could claim a generational familial tie to their town and the status of "good person." Yet, meanings about race are also embedded in how people make class distinctions within rural areas, an issue I further discuss elsewhere (Kazyak 2011a). Likewise, I also address in detail an analysis of how gender shapes the experiences of rural gays and lesbians (Kazyak 2011b).

Government agencies and researchers generate multiple definitions of "rural." Definitions based on population size define areas with fewer than 2,500, 10,000, or 50,000 people as "rural" (USDA 2007). I began the project with intentions to recruit participants only from areas with fewer than 2,500 residents. However, since many people contacted me lived in towns with larger populations and still thought of their communities as rural, I used the more expansive definition that includes areas with populations less than 50,000. Half of the interviewees were living in areas with populations of less than 2,500. Seven people were living in towns with populations less than 10,000 (all of these towns had populations between 3,000 and 5,000) and eight were living in towns with population sizes more than 10,000, but under 50,000.

The population of the areas where people lived varied, as did the way they described those areas. Molly outlined some of what is in her town, including "one grocery store, [a] post office, [a] dollar store, a health food store, a pharmacy, a video store, [a] physical therapy place." Chelsea explained her town has having "one stop light. [there's] not much here, [we're] lucky to have a gas station." Joan described living a few miles outside town and being surrounded by hills and woods. Others, including Leila and Chelsea, had neighbors nearby. While some characteristics of their towns differed, all interviewees described their towns in a similar way to Tara, who said: "Everybody knows everybody, and if they don't, they know your family...it's homey, it's friendly, people wave at each other. People from the city think you're nuts, but that's what we do!"

There was also a range of reasons why people were living in rural areas. Within the formula story that links queer sexuality with urbanism, it is assumed that gays and lesbians who can leave rural areas will do so. ${ }^{6}$ Yet, I interviewed people who could "choose" to leave and who also "chose" to migrate back. Among those who migrated to cities and then migrated back home, Alice and Adam returned to care for aging family members. For some interviewees, their partners brought them to the area. Nate saw moving back to a small town as allowing him to start a business. Others talked about deciding to move to a smaller town when they had children. Leila and Nancy, for instance, "wanted our children to experience that same thing that we experienced" in terms of going through school with the same group of people. Below, I analyze how their interpretations of geography matter for the stories they tell about their sexualities.

\section{Modifying Cultural Narratives About Fleeing and Urban Queer Cultures}

\section{Coming Out \& Nuanced Understandings of Rurality}

Geography is central to narratives producing gay and lesbian cultural identities insofar as urban space is assumed to be the site to come out and find queer community. As they make sense of their experiences, rural gays and lesbians negotiate in two pri-

6. The assumption that people will migrate out of rural areas if they can is not only relevant to gays and lesbians, but here I am most interested in its importance in narratives about gay and lesbian sexual identity. 
mary ways the formula story that coming out can only happen in urban areas. People who had not lived in a city, including Rich, Chelsea, Tara, and Lisa, rejected this understanding. Rather, they understood it as something only others used to make sense of their experiences. Tara, a white woman in her mid-40s, was living in an area where her family had lived for three generations. When talking about her experience of coming out, I asked if she ever thought about migrating to a city, bringing up the assumption that "if you were raised in small town and realize you're gay, then you want to flee immediately and move to a big city" because "it must be terrible and you must want to escape." She replied: "No, I didn't feel like that at all. You mean to flee to hide in the big city? Or go to where I would feel more comfortable? I personally wouldn't flee to a big city, because I don't like them." Lisa, who is in her fifties and has lived in her town for the past twenty-nine years, brought up that even though she did not move to a city, others have questioned her ability to be out as a lesbian in a small town. She said: "People have asked [if I] have ever had somebody be really really rude or scarily aggressive toward [me] or anything like that because [I'm] a lesbian. And I never have."

Yet for some, the link between fleeing to an urban space and coming out did resonate with their own experiences. Alice, a white woman in her early 40s, had lived in a city for ten years before returning to the area where she was raised to take care of her mother. She talked about the city as a place where "my world started opening up more," insofar as she met other lesbians. Robert is a white man in his early 40s who has been living with his partner in a small town for the past ten years. He had also lived in an urban area and his narrative echoed that of Alice's. He described his migration to an urban environment as connected with his coming out because: "I still hadn't said the words out loud. It wasn't until another gay couple looked at me and they said, you're gay, you know. And to me it just kinda all of a sudden became real." Although migration was linked to coming out for Robert and other interviewees, their migration back to rural areas is a modification to the formula story. The following quote from Jake underscores that modification. Jake had a similar migration experience to that of his partner Robert: he grew up in a small town, lived in a city, and then migrated back to a rural area (a different one than where he grew up). Reflecting on those migrations, Jake said: "It seems like a lot of gay people...wanna be in New York City or Los Angeles because there's so much more opportunity and you can kinda fit in and stuff...and for me, I was just the opposite...I was so very happy to get to move out of the city." That Jake sees himself as "just the opposite" of "a lot of gay people" because of his desire to move out of the city highlights how embedded the city is in narratives about gay identity, and how significant a modification it is to claim gay and lesbian identities in rural areas.

While there are differences in how rural gays and lesbians engage with the narrative of fleeing rural space to come out, both groups understand "rural" in nuanced ways. The formula story scripts rural space and people inhabiting it as intolerant of gays and lesbians (thus making it necessary to migrate to an urban space to come out). The people I interviewed modify this understanding by drawing on their interpretations of rural space and individuals as complex, changing entities. That rural is not monolithic makes it possible for them to narrate gay and lesbian identities in rural places even though the formula story denies this as a possibility.

One way that interviewees demonstrate a nuanced understanding of rural people is in their articulation that attitudes towards gays and lesbians in rural areas have changed over time. Consider the following story Robert told me about his nephew (his sister's son) and the nephew's friends coming to visit him and his partner. After the visit, Robert told me his sister emailed to thank him for letting them stay and also relayed an exchange between the nephew and his friends. Here Robert provides the 
details of that exchange: "My nephew, on the way down in the car said [to his friends] "now my uncle is gay and if you have a problem with that you can just stay home.'" Robert thought that this exchange "really speaks a lot" because "when I was that age, those thoughts would have never occurred to me. So you know that that area is completely changing." His story reveals how the people I interviewed, even if they had different experiences in small towns growing up, have recent experiences that illustrate to them that not all rural people are homophobic or intolerant.

Additionally, people made distinctions among rural areas, another example of how interviewees understand rural space in nuanced ways. Consider Nate, a fiftyyear old man living in a small town for fifteen years, but one that was different from where he had grown up. He had also lived in a city and talked about his decision to move to a smaller area and how he decided which area. Talking about the town he did not choose to move to, he said, "I just decided it reminded me too much of the town I grew up in and it brought back the fear that I felt when I was growing up." Erin, a woman in her early fifties who had been living in a small town for two years, likewise narrated differences among rural areas. She compared her town to others nearby, suggesting that: "I think [mine] is much more progressive, probably higher educated, higher income people probably than [surrounding area]. In [surrounding areas] [people] would be much less tolerant." As both of these quotes reveal, people living in rural areas understand "rural" or "small town" in nuanced ways. For Nate and Erin, these spaces are not imagined or experienced as monolithic, totally backward, or unwelcoming as they are in the cultural narrative that suggests rural gays and lesbians must flee. By making distinctions between small towns, people like Nate and Erin are able to narrate an alternative understanding to the idea that it is impossible to be out as gay or lesbian in rural areas.

\section{Gay and Lesbian Communities \& Urban-Rural Distinctions}

While the people I interviewed modified the link between urban space and coming out, they did narrate an understanding that links urban space and queer events, cultures, or communities. Jenny, a white woman in her early thirties was living (and came out) in a rural area where her family has lived for three generations. She had this to say about the area: "There really isn't a gay and lesbian community around here. [When we travel] we try to get as much of that culture as we can because there's none here." Such an understanding was articulated across the interviews. For some, the link between the city and gay communities was imagined (i.e. they had limited or no connection to queer urban communities). Yet others, particularly those who had migrated to cities before migrating back to rural areas, did talk about their many different experiences in urban gay and lesbian communities.

Importantly, people made sense of their experiences in queer urban spaces (whether real or imagined and whether positive or negative) through interpretations about urban/rural differences. In addition to illustrating that interviewees make distinctions between "urban" and "rural" gays and lesbians, I also address the two consequences these distinctions create. First, making distinctions between rural and urban gays allows rural gays and lesbians to construct sexual identities in rural locales. The people I interviewed make sense of their experiences in such a way that distinguishes between expectations in rural and urban contexts. Their narratives posit the city as the site of gay pride parades and other exciting ways to be gay or lesbian. In doing so, their stories modify the component of the formula story that says gay and lesbian identities cannot be constructed in rural areas. They replace it with the narrative that people in rural areas do not articulate an urban gay identity, and not always 
(or only) out of an inability to, but also out of a lack of interest in doing so. The second consequence of the fact that interviewees make distinctions between urban and rural gays is that their narratives reify "urban gays and lesbians" by denying the diversity among gays and lesbians in cities.

When describing experiences in urban queer communities, rural gays and lesbians create distinctions between "rural gays" and "urban gays." Thus, the city is imagined not as the only place to be gay, as in the formula story, but it is imagined (and experienced) for some as a site inhabited by certain kinds of gays and lesbians. Consider the following quote from Ethan about his experiences in urban queer cultures. A white man in his late 30s, Ethan had lived in a number of different small towns and cities before moving to his current place of residence, where he had been living for the past ten years. Ethan explained that:

I don't really fully relate to gay culture and I don't really like it. I guess I'm kinda a part of it [because] I go to the bars a lot and I have a lot of gay friends. I appreciate the city where there is more of a gay community, but at the same time, I just don't enjoy a lot of it.

Ethan's quote shows the link between urban space and gay community, culture, and bars as "the city" is "where there is more of a gay community." It also highlights how he understands urban gay culture as something he does not "fully relate to" or "enjoy." Likewise, talking specifically about his experiences in urban gay bars, Adam said:

It wasn't real welcoming I guess. I've been in bars with my father in [my small town] and people knew each other, it was a very friendly, laid back place. [At the gay bar] no one just came up to talk to you...so it just didn't feel warm and friendly.

Adam, like Ethan had lived in a city before returning to the small town where he was raised. Adam also draws on his understanding of urban/rural differences when making sense of queer urban cultures. For him, the distinction between urban and rural bars and the degree to which they are welcoming rested on the degree to which "people knew each other."

Another way rural gays and lesbians draw on their understandings of urban-rural differences when making sense of urban queer cultures is in distinguishing between the "exciting" urban and "boring" rural gay. Throughout my interview with Tara, she stressed "I'm boring" several times. As she put it at one point: "I am very very very very very boring. If there's a rock lying in the road, that rock has more action than I do!" In a similar manner, Laura described herself as not doing anything exciting. Laura is fifty-five years old and living in an area that has a larger population than the small town where she was raised, but one that she still sees as having a small town feel. She juxtaposes the lack of excitement in her life with representations she sees of urban gays and lesbians participating in gay pride parades. In explaining her frustration with such representations, she said: "There are some of us that are just old married people, you know. We don't do anything exciting. We go to work, go home, cook breakfast, dinner, lunch, whatever, do laundry, go canoeing maybe, do some dishes." In contrast to people like her, she says at urban gay pride parades "you've always got the people who are so extreme." For Laura, gays and lesbians in urban environments who participate in gay pride parades are "extreme" and exciting and, importantly, very different from gays and lesbians in rural areas like herself. Being able to draw a clear boundary between "rural gay" and "urban gay" allows people like Laura to craft sexual identities that they narrate as unique to rural locales, even though the formula story denies this as a possibility. Yet the distinction also reifies "urban gays and 
lesbians" and denies any diversity or complexity of gay identities that exist in urban spaces. Presumably, urban gays and lesbians who participate in gay pride parades also do the things Laura ascribed to herself. Yet in her narrative, urban gays and lesbians who are "extreme" at pride parades cannot also be people who are "just old married people" like herself.

That drawing on rural-urban differences provides gays and lesbians a resource to construct sexual identities they understand as specific to rural locales is especially salient in Robert's narrative. Robert came out in an urban locale. His participation in urban queer cultures has shaped both his ability to construct a gay identity and to construct one that he sees as distinct from those in urban locales. Reflecting on his time in an urban place, he said he "just kinda explored what it meant to be gay," which included being "involved in a gay organization [that] organized a lot of pridefest parades" and going to "bars and parties." He then explained that he has "kinda come back a little bit from that because I just found it so empty." For Robert, the ability to "come back" from what he did in urban environments was connected to his migration back to a rural area. Reflecting on that migration and its relation to his sexual identity, he said: "It wasn't until I moved back home that I was like, you know, I can define myself. I can say, this is who I am and this is what it means for me to be gay (my emphasis added)." Robert makes sense of his gay identity differently in the city than in a rural area. Indeed, he understands rural areas as offering more flexibility in terms of how he makes sense of his sexuality. Particularly, his quote demonstrates that he understands his gay identity in rural spaces as somehow more personal: "This is what it means for me to be gay." The rural becomes the imagined (and experienced) space where he is "free" from cultural understandings about "what it means to be gay." Unlike the longing to escape to the city (Weston 1995), these narratives posit a desire to escape from the urban to the rural. If this is the case, what does happen in rural areas? If living in small towns means not being held accountable to urban-based understandings about what it means to be gay or lesbian, then what do those sexual identities look like in rural locales?

\section{Drawing on Interpretations of Rurality in Constructing Gay \& Lesbian Identities}

In this section I discuss how gays and lesbians living in rural areas construct sexual identities. Using their interpretations of rural culture, they craft understandings about what it means to be out, visible, and accepted as gays or lesbians in rural areas. In doing so, they modify cultural understandings that narrate gay/lesbian identities in rural areas as closeted, hidden, and oppressed.

\section{Being Known as a Good Person \& Having Ties to Rural Community}

In narratives about expectations and experiences of their sexual identity being accepted in rural areas, interviewees point to being known as a good person within their communities and having ties to the community and people. As Nate explained, "I think it depends on how long you've lived there and how much you're embraced by the community...if you're a part of the town, they accept you much easier." For many people, being known as a good person was synonymous with having familial ties to the community; the way in which they were known as a good person resulted from growing up in the same or nearby town, thus having ties to the area and the ability to lay claim to being a part of it. Consider the following example from Tara who is living in a town nearby where her family has lived in for generations. When responding to my question if she had any concerns when she first moved to her town as an out lesbian, she said 
"not at all" and offered the following explanation: "See now the reason why is [that] most people know me. There's not hardly anybody in that town that doesn't know me or know someone that knows me. So I had no problems." Jenny, who is living in the same area where she grew up, has a similar understanding about why her sexuality is accepted. Here she is referring to her partner, who was living (and grew up) in an urban environment before migrating to their current rural locale. She reflected: "[My partner] was more surprised by the reaction of people and how open and accepting they were. I just assumed people seem to like me enough." Unlike her partner, Jenny had ties to the area by nature of having lived there and her family having lived there for generations. For Jenny and Tara, the tie to their rural community - "being known" - often served as a route to not only just being known, but being known as a good person. As Jenny put it, given that "people seem to like me enough," she was expecting people to accept her sexuality and thus was not surprised when they did.

This finding has important implications in light of the fact that interviewees described their communities as being almost entirely or entirely white. That almost all of the people I interviewed are white and had familial ties to the area no doubt shaped their interpretation that others in the community recognized them as "good people." One person of color, Molly, who was in her early twenties, mentioned her race and the fact that she came "not from a family around here" as a reason why she thought she initially experienced discrimination as an "outsider" when she moved to her small town. After having lived there for three years, she said that "the whole community has learned to accept me," an acceptance that is likely tied to the fact that she is partnered with a white woman who has familial ties to the area. Gays and lesbians of color living in rural areas who cannot lay claim to having ties to the community for generations likely do not have the same route to acceptance of their sexual identity.

Yet, having generational familial ties to the area is not the only available route to being recognized as a "good person," as suggested by Justin's experience - a biracial man in his early thirties. He grew up in a rural area and for the past eight years had been living in a small town. Despite not having had grown up there, or having family who lived in the town for generations, Justin still felt accepted as a gay man. As he articulated: “This town doesn't care if you're gay or straight or whatever. As long as you're a good person, they could care less." How Justin described his experiences underscored a sense of being known by people in the town as well as embracing small town life. For instance, Justin described himself as a "country boy" who "love[s] the small towns." He explained: "I enjoy that I talk to people and not feel that I have to be somebody else. The only think I hate about this town is that everybody's on a first name basis, so I know all these people but I don't know their last names, so I can't remember who they are." Further, Justin said, "I don't have a rainbow flag out...I don't have anything that identifies me as gay, but it's just like, here in town, they know that I am and I don't have to hide it, so that's the good thing." For Justin, simply being known is a route to being known as a good person, which is a route to having one's sexuality known. This route to sexuality being known and accepted is understood as unique to rural life and as distinct from other routes that, as explained in the previous section, are seen as tied with urbanism (e.g. displaying a rainbow flag). As a biracial individual without familial ties to where he is currently living, Justin's experience additionally highlights that race and generational ties are part, but not the entirety, of how the status of "good person" can be achieved.

The importance of being known as a good person and having ties to the area underscores that interviewees emphasized how they are treated face-to-face to gauge acceptance rather than, for instance, how neighbors think about gay or lesbian sexuality politically. Consider the following exchanges between Andrea and Chelsea, a 
couple living in an area whose population is less than 2,500 and which they described as "the epitome of small town life." They had both grown up in small towns, but Andrea had lived in a city before migrating to where Chelsea was living. Commenting on her experiences there, Andrea said that although she did not really know what others might "say about me behind my back," she did know they treated her well face-to-face. Chelsea agreed and the following story demonstrates this. She said, "You never know if anybody says anything bad about me at work, but I do know that one of my co-workers called [Andrea] to wish her a happy birthday. It was on his own spare time, he just called to say 'hey,' which was cool." The value placed on how people interact with one another rather than what they might think about each other outside of those interactions or their political beliefs makes sense given that many people described that living in a rural environment cultivates a specific way of relating to people. Lisa asserted that "the people skills are different" for rural and urban dwellers. Giving more detail about these skills, she said, "People are more involved with each other and more inclined to avoid negatives toward each other and they're not nearly so quick to discount people [or] ignore and cross them off their list." In contrast, she described that people in the cities are "more self-contained" and "more interested only in their own standards." Unlike in cities, Lisa asserted that "quickly in a small town environment, if you alienate this one and that one, pretty soon you've got nobody." Within this context, it makes sense that people think it is important to be treated well in everyday interactions and can disconnect how others treat them from knowing how others might "actually" think about their sexuality. However, unlike how the rural gays and lesbians in this study described their experiences, others express anger and disappointment at what they perceive to be a homophobic climate (Oswald and Culton 2003). Moreover, the experiences described by interviewees differ from those who were raised in rural areas but live in cities (Oswald 2002). When returning to visit their rural communities of origin, many feel different and distant from their family members (Oswald 2002).

\section{The Close-Knit Nature of Rural Life}

Interviewees repeatedly characterized rural locales as creating a small, close-knit, everybody knows everybody and their business atmosphere. In talking about what he loves about his small town Nate explained:

You go into the grocery store and you know the check-out people [and they] will call you by name and you go into the gas station [and] they know you, you go into the bank, wherever you go, they know you, and it's just a very, comforting, supportive, situation.

Narratives of what it means to be out, visible, and recognized were informed by such characterizations of rural life. Specifically, the understanding of rural life as close-knit informed narratives that exist in tension with each other. Rural life facilitates both anonymity and visibility, both implicit and explicit recognition of sexual identity, and both a "live and let live" attitude and greater interconnectedness. That interviewees articulated these conflicting narratives underscore the multiple interpretations of rural as well as the varied ways people make sense of gay and lesbian identities within a rural context.

In one narrative, the close-knit atmosphere of small towns facilitates an implicit recognition of sexual identity, yet one that is not necessarily explicitly talked about. Here, the interpretation that rural spaces are close-knit matters insofar as people believe a "live and let live" attitude emerges from such an environment. This "live and 
let live" attitude translates into a certain degree of artificial anonymity given that sexual identity is not explicitly recognized. ${ }^{7}$

The theme of gay identity being implicitly acknowledged emerged in several interviews. Molly, for instance, explained, "There are people who are gay, but people just don't talk about it in the community." Likewise, Alice said that though she had not explicitly come out to her mother, she had overheard her mother explain to her brother that she was a lesbian. The lack of explicit acknowledgement is connected to an understanding that equates "rural" with a "live and let live attitude." The following quote from Erin illustrates the "live and let live attitude" and rural living. She says: "It's just like, I'll leave you alone, just leave me alone, we'll live our lives. Country is kinda like live and let live." Others agreed with Erin's assessment and offered their understandings about how the live and let live rural mindset leads to an implicit recognition of gays and lesbians. For instance, in talking about others in her small town, Lisa offered, "There are a lot more good-hearted people who are at least accepting enough to let live and let live." The "live and let live attitude," understood as unique to rural areas, translates into a lack of explicit acknowledgement of gays and lesbians. The following quote from Andrea illustrates the link:

In the city, if somebody...has a problem with you being gay [they can] get in your face and tell you about it because there's a chance they're not gonna see you again. Whereas...somebody around here is gonna be less likely to come up and say something...because we're gonna see them around, like we're their neighbors.

In Andrea's understanding the fact that rural life is a close-knit atmosphere, one where people "see them around" and are "their neighbors," facilitates a lack of explicit acknowledgement ("somebody around here is gonna be less likely to come up and say something"). Molly offered a similar understanding, saying that "people [here] are so laid back, that they're like, your business is your business." In contrast, Molly interprets people living in cities to be "much more opinionated about being homophobic." Further explaining the difference she sees between urban and rural people, she says that since people in cities are more opinionated: "They'll voice it more, whereas people here wouldn't. If they have an opinion, they would keep it to themselves."

Across these quotes, people asserted that others do not explicitly recognize their sexual identity (either positively or negatively). Rather, others might know about and tacitly accept their sexual identity, which interviewees connect to the close-knit nature of rural life. A sort of artificial anonymity emerges in these narratives. The city is associated with anonymity insofar as it is a site where others might not know you or what you are doing; and, indeed, this anonymity was seen as particularly important for the ability to come out as gay or lesbian. In contrast, in these narratives, a sense of anonymity emerges not from one's actions not being known, but from those actions not being explicitly acknowledged. In rural locales, everyone might know everyone else's business, but there is also a tacit agreement that, as Molly described, "your business is your business" and we should "live and let live." Further, the sense of anonymity that stems from the close-knit nature of rural life is tied to a sense of safety. Unlike the city which, in Andrea's quote, offers a degree of anonymity to people who might express hostility toward gays and lesbians, the fact that everyone knows every-

7. The lack of explicitness around gay/lesbian sexuality mirrors historical research on same-sex desire and/or identity pre-gay liberation. Scholars analyze, for instance, how discretion characterized lesbian life in the early 20th century (Kennedy 1996). Here I am most interested in illustrating how people attributed the implicit recognition of gay/lesbian sexuality in rural areas to their interpretation of rurality, namely the close-knit nature and its consequence of a "live and let live" attitude. 
one (and will continually see them around), lessens the opportunity to express such hostility in rural areas.

This narrative exists in tension with another narrative that ties the close-knit nature of rural life to constructions about how sexual identity is visible, explicitly recognized and accepted. Many discussed their sexual identity having been explicitly recognized or having explicitly come out as being tied to the close-knit nature of rural life. In this narrative, unlike artificial anonymity, the close-knit nature of rural life translates into a sense of greater interconnectedness. The interconnectedness then translates into the ability for visibility, which may create tension for the live and let live attitude.

The explicit recognition of gays and lesbians and its tie to the close-knit nature of rural life is evident in the following stories from Andrea and Nate. In talking about why she is out, Andrea described that "everybody knows everybody...if one person knew I was a lesbian, the whole town would know. So, it's just easier to be upfront about it." Others echoed the sense that their sexual identity is explicitly recognized through the fact that in rural locales, everybody knows everybody and news travels fast given the interconnectedness of the close-knit rural life. Laura reflected on what it was like when she first came out: "It didn't take long for it to get all around town." She was told how people "were talking about it at the coffee table" in a diner later that day. Nate explained that people in town found out about the break-up of his relationship without him being the one to announce the news. Nate told the following story:

When we broke up...I was walking down the street...[and a] bus driver saw me... and she said, "Oh there's [person's] boyfriend!" And another person on the bus said, "You heard they broke up didn't you?" [She said]: "No! I can't believe they broke up!"

He explained that "this whole conversation got relayed to me later" and suggested that "only in a small town!" would such a thing happen. His story reflects that one narrative about what it means to be gay in small towns is informed by a sense that everyone knows everyone (and their business) and word travels fast. The closeknit nature translates into a sense of interconnectedness unique to rural areas (an interconnectedness that facilitates a "grapevine" where news travels quickly through all parties who are connected) which then translates into a sense of why and how people are out and their sexuality and same-sex relationships are explicitly recognized. ${ }^{8}$

The close-knit nature of rural life also facilitates a visibility of sexuality that occurs through being seen around town with a same-sex partner. Rather than be able to remain anonymous as one could in the city, the close-knit, interconnected nature of rural life makes it nearly impossible to go unnoticed, thus fostering a sense of visibility. For instance, when describing the extent to which people know she is a lesbian, Lisa replied in reference to her partner. She said, "We're always together. I mean in a small town like this, you do get seen when you go to the ice cream place or to the bank or something and if we're not seen alone, we're seen together." Likewise, Andrea and Chelsea thought that "everybody in town knows" about their relationship because "not only does word travel fast, but like, we go places together... we go to the grocery store and shop together" and "we hold hands" and "we walk around the yard, look at the flowers, and hug and smooch." Tom, a white man in his early forties who was living in the same area where he grew up, agreed. When discussing how other

8. Again, I am most interested in the fact that the implicit/explicit recognition underscores that people make varied interpretations of how rural "everyone knows everyone" matters for their sexual identity. The explicit narrative resonates with recent shift in gay/lesbian identity to be out (Seidman 1999), but the ages of the people discussed here range from late 20s (Andrea) to mid-fifties (Nate; Laura; Lisa). 
people have responded to him and his partner and the degree to which people know he is in a same-sex couple, Tom explained that he and his partner are not "the type to hang the gay pride flag out in the yard" and "neither one of us comes off as...stereotypically gay." Rather, like the previous interviewees, his sense of being visible is tied to being seen with his partner: "We go down to [the one bar in town]... it's like, wherever I'm at, [my partner] is at, and wherever [my partner] is at, I'm at, when we're at [the one bar in town], it's not like either one of us goes while we're by ourselves, we only go when we're together." The route to visibility in his story is tied to his understanding of rurality. Again, it is understood as a route that is distinct from other routes that are described previously and understood by interviewees as more tied to urban spaces (hanging gay pride flag). In these stories, visibility occurs and is sustained via the interconnected nature of rural life and being seen at various places (the bank, the grocery store, the ice cream place) with the same person.

\section{Conclusion}

This article details how gays and lesbians draw on interpretations of space in narratives about their sexual identities. Rather than disavow gay identity, this work illustrates how rural gays and lesbians modify cultural narratives about gay and lesbian sexualities. By drawing on rural/urban differences to make distinctions between "urban gays" and "rural gays," they construct sexual identities they understand as specific to rural locales. In their stories about what it means to be gay and lesbian in the country - to be out, visible, and accepted - people draw on narratives about being known as a good person, having long-standing ties to the community, and living in a context where word travels fast through close-knit networks.

Consistent with the work of Mary Gray (2009) and Arlene Stein (2001), the findings presented here reveal the importance in rural contexts of being one of the locals. That the people I interviewed who were living in rural areas had grown up in those areas or neighboring ones no doubt shaped their ability to make sense of themselves as out and accepted gay and lesbian members of their communities. Being a local and constructing a gay or lesbian identity were not seen in tension with one another. Strikingly, the narratives in this study about visibility and acceptance differ from the ways in which some of Gray's participants asserted non-normative sexualities. While Gray documents how rural gays and their allies are politically active, most of the people I interviewed understood the tie between activism and gay and lesbian identities as an urban phenomenon. Also, the people I interviewed would consider pride websites or doing drag as accounts of gay and lesbian identities attached to urban landscapes. In this way, people maintained the importance of geographic distinctions in how they narrated the differences between rural and urban gays and lesbians. Future work could explore tensions that might arise among rural gays and lesbians, given that some of the ways that Gray found rural queer youth asserting queer identities were understood by the people I interviewed understand as urban-based.

Like Howard (1999), my work documents how rurality produces rather than constrains the construction of gay and lesbian sexualities. Unlike Howard's analysis that privileges queer desire rather than identity, my work foregrounds identity: the people I talked with do identify as gay or lesbian and the majority find it important for their friends and family to recognize those identities. The focus on identity reflects that I only recruited individuals who identify as gay or lesbian and that half of the respondents were recruited through LGBTQ-specific venues. Further, the burgeoning scholarship addressing non-metropolitian gays and lesbians highlights the variation in how people make sense of space and sexuality and underscores the need for future 
analyses to address how social characteristics, including age, race, class, and gender, shape this variation.

Indeed, differences between Gray's findings and those presented here in part reflect the differences between the groups of people we studied. Unlike her participants, the people I interviewed are older. Many of them had migrated to an urban place and then migrated back to a rural place and not all would characterize that migration back to a rural place as compelled by obligation. Other important demographic differences include that many of the interviewees in this study do not see themselves as lacking in economic resources and likewise are not necessarily living in areas that are impoverished. Class is important to another way that participants construct a nuanced understanding of "rural." Participants make distinctions between "hick" and "redneck" - distinctions that differentiate rural areas as well as people within them. They understand themselves as "hicks" and not "rednecks" and equate "redneck" with being close-minded. Thus these classed distinctions further strengthen the disruption of the cultural narrative that conflates all rurality with homophobia (Kazyak 2011a). Additionally, that many of the people I interviewed are coupled mattered for how they made sense of gay and lesbian visibility in rural areas. Having a same-sex partner along with an interpretation of rural as close-knit produces a narrative about visibility that would be less possible for non-coupled gays and lesbian. The coupled status of participants is also particularly important given the meanings of gender presentations in rural areas. While nonfeminine gender presentations are often conflated with lesbian sexuality (Kennedy and Davis 1993; Moore 2006), participants in this study noted the degree to which nonfeminine gender presentations are in fact acceptable and typical for all women in rural areas, regardless of sexual identity. Therefore, since it is hard to distinguish between Midwestern (straight) women and lesbians and in small towns, being seen with a same-sex partner matters more for visibility than do nonfeminine gender presentations (Kazyak 2011b).

Even as interviewees narrated nuanced experiences of rurality, people nonetheless often erected boundaries between rural and urban. It is important to note how interviewees' narratives at times reify "urban gays" in much the same way that the formula story reifies "rural gays." Interviewees' stories illustrate that reifying "urban gays" discounts nuances among gays and lesbians living in urban environments and works to deny recognition of potential similarities across contexts. For instance, in some accounts, going to pride parades was conflated with urbanity and excitement and understood in opposition to being married and boring and just going about one's day-to-day life. Yet, of course, gays and lesbians who participate in pride events might engage in these latter behaviors as well. Some urban gays might disavow pride in many of the same ways as rural gays do. Here I have mainly discussed the implications of rural gays and lesbians narrating distinct differences between "rural" and "urban" with regard to their ability to construct sexual identities in rural contexts, a possibility that cultural narratives deny. Yet what are the implications of the reification of "urban gays" for gay and lesbian social movements? Also, (how) does urban renewal or anti-gay political activism shape the narratives rural gays and lesbians create about what it means to be gay or lesbian in cities? ${ }^{9}$ These questions warrant attention in future research.

9. Building on work that analyzes the consequences of urban renewal and gentrification for urban queer populations, specifically around gender and class stratification (Delaney 1999; Knopp 1997; Rubin 1984), an important question to consider is how these processes matter for people's interpretations of who the gays and lesbians are who live in cities. Likewise, research addresses how claims of anti-gay religious organizations demonize and stereotype gays and lesbians and gay communities (Fetner 2001). Future work could assess if and how such stereotypes overlap with the narratives that rural gays and lesbians produce about "urban gays." 
The focus in this article on personal and cultural narratives, namely on how rural gays and lesbians modify the circulating formula story about their sexual identities, underscores that "narratives beneficial in encouraging change at one level might not be so beneficial at another level" (Loseke 2007, 680). Disrupting the link between urban locales and gay identity, assumed to be essential in cultural narratives, is beneficial at the personal level for gays and lesbians who want to stay put in rural areas and believe they have their sexuality acknowledged and accepted. Yet the disruption might constrain gay and lesbian organizational efforts to rally political support for gay rights, for instance, given the absence of the "oppressed rural gay" stock character. Further, this work draws attention to the fact that people have multiple understandings about what progressive social change means. The stories interviewees told raise questions about what it means to be political or radical. People's narratives reveal a contradiction insofar as they simultaneously distance rural gay identity from "activism," and yet frame the act of staying put in rural places as political. Consider the following example from Chelsea who explained why she wanted to stay in her rural area if she and her partner have children. She said:

I just think that the more you expose them, the more you educate people about our lifestyle, the better off we're gonna be as a whole. If you keep pigeonholing, and segregating people, and not exposing them to our lifestyle, their kids are gonna be brought up just like we were-not knowing what the word lesbian is. And if it's that one classmate that has two mommies that teaches some kid that it's ok, then good, we're making a step forward.

For Chelsea, migrating to the city would reflect a "pigeonholing" of gays and lesbians that would continue a trend she sees as negative: people in rural areas not knowing gays and lesbians. Her account asks us to consider how, for some, staying put entails an understanding of self not as naïve or oppressed, but as making a conscious, political decision. Yet, of course, other people's accounts of gay identity in rural areas rests on narrating rural contexts as providing the opportunity to construct sexualities that are not aligned with making a political statement. Chelsea's quote also indicates that she understands staying put in a rural area as a "step forward" because it involves others in the area becoming aware of gays and lesbians. Indeed, Chelsea, like other interviewees, told stories about positive interactions with heterosexual neighbors and co-workers and about the different ways she thought her sexuality is recognized and accepted by heterosexuals in her small town. Future work could incorporate the understandings of heterosexuals and interrogate if they draw on similar narratives about rurality and rural-urban differences when making sense of the gays and lesbians living with them in rural areas.

Acknowledgments - I would like to thank the people I interviewed for this project for their time and willingness to share their stories. I also owe many thanks to Laura Hirshfield, Nadine Hubbs, David Hutson, Zakiya Luna, Katherine Luke, Karin Martin, Helen Moore, Carla Pfeffer, Gayle Rubin, Kristin Scherrer, Margaret Somers, Alford Young, Jr., as well as the editors and the anonymous reviewers for Qualitative Sociology for their helpful feedback on earlier drafts of this article.

\section{References}

Abraham, Julie. 2009. Metropolitan lovers: The homosexuality of cities. Minneapolis: University of Minnesota Press.

Achilles, Nancy. The development of the homosexual bar as an institution. 1967. Reprint, In Social perspectives in lesbian and gay studies, ed. Peter M. Nardi and Beth E. Schneider, 175-182. New York: Routledge, 1998. 
Armstrong, Elizabeth A. 2002. Forging gay identities: Organizing sexuality in San Francisco, 1950-1994. Chicago: University of Chicago Press.

Bell, David. 2000. Farm boys and wild men: Rurality, masculinity, and homosexuality. Rural Sociology 65(4): 547-561.

Bernstein, Mary. 1997. Celebration and suppression: The strategic uses of identity by the lesbian and gay movement. The American Journal of Sociology 103(3): 531-565.

Black, Dan and others. 2000. Demographics of the gay and lesbian population in the United States: Evidence from available systematic data sources. Demography 37(2): 139-154.

Boulden, Walter T. 2001. Gay men living in a rural environment. Journal of Gay \& Lesbian Social Services 12(3-4): 63-75.

Boyd, Nan. 2003. Wide open town: A history of queer San Francisco to 1965. Berkeley: University of California Press.

Brekhus, Wayne. 2003. Peacocks, chameleons, centaurs: Gay suburbia and the grammar of social identity. Chicago, IL: University of Chicago Press.

Broad, K.L. 2002. Social movement selves. Sociological Perspectives 45(3): 317-336.

Chauncey, George. 1994. Gay New York: Gender, urban culture, and the making of the gay male world, 1890-1940. New York: Basic Books.

Coby, Paul, and Peter Welch. 1997. Rural gay men in Northern New England: Life experiences and coping styles. Journal of Homosexuality 33(1): 51-67.

Crawley, Sara L., and K.L. Broad. 2004. 'Be Your(real lesbian)self': Mobilizing sexual formula stories through personal (and political) storytelling. Journal of Contemporary Ethnography 33(1): 39-71.

D'Emilio, John. 1983. Capitalism and gay identity. In Powers of desire: The politics of sexuality, eds A. Snitow, C. Stansell, \& S. Thompson. New York: Monthly Review Press.

Emerson, Robert M., Rachel I. Fretz, and Linda Shaw. 1995. Writing ethnographic fieldnotes. Chicago: University of Chicago Press.

Fellows, Will. 1996. Farm boys: Lives of gay men from the rural midwest. Madison: University of Wisconsin Press.

Fetner, Tina. 2001. Working Anita Bryant: The impact of Christian anti-gay activism on lesbian and gay movement claims. Social Problems 48(3): 411-428.

Fine, Gary A., and Corey D. Fields. 2008. Culture and microsociology: The Anthill and the Veldt. The ANNALS of the American Academy of Political and Social Science 619(1): 130-148.

Gates, Gary J. 2006. Same-sex couples and the gay, lesbian, bisexual population: New estimates from the American community survey. Los Angeles: The Williams Institute. http://www.law.ucla.edu/williamsinstitute/publications/Policy-Census-index.html

Gates, Gary J. 2007. Geographic trends among same-sex couples in the U.S. census and the American Community Survey. Los Angeles: The Williams Institute. http://www.law. ucla.edu/williamsinstitute/publications/Policy-Census-index.html

Gergen, Kenneth J. 1994. Realities and relationships. Cambridge: Harvard University Press.

Ghaziani, Amin. 2008. The dividends of dissent: How conflict and culture work in lesbian and gay marches on Washington. Chicago: University of Chicago Press.

Gray, Mary L. 2007. From websites to Wal-Mart: Youth, identity work, and the queering of boundary publics in Small Town, USA. American Studies 48(2): 5-30.

Gray, Mary L. 2009. Out in the country: Youth, media, and queer visibility in rural America. New York: New York University Press.

Halberstam, Judith. 2005. In a queer time and place: Transgender bodies, subcultural lives. New York: New York University Press. 
Harry, Joseph and William B. DeVall. 1978. The social organization of gay males. New York: Praeger Publishers.

Hennen, Peter. 2008. Faeries, bears, and leathermen: Men in community queering the masculine. Chicago: University of Chicago Press.

Herring, Scott. 2007. Out of the closets, into the woods: RFD, country women, and the post-stonewall emergence of queer anti-urbanism. American Quarterly 59(2): 341-372.

Holstein, James A. and Jaber F. Gubrium. 2000. The self we live by: Narrative identity in a postmodern world. New York: Oxford University Press.

Howard, John. 1999. Men like that: A southern queer history. Chicago: University of Chicago Press.

Johnson, David K. 1993. The kids of fairytown: Gay male culture on Chicago's near north side in the 1930s. In Creating a place for ourselves: Lesbian, gay, and bisexual community histories, ed. Brett Beemyn, 97-118. New York: Routledge.

Johnson, Colin. 2003. Columbia's orient: Gender, geography, and the invention of sexuality in rural America. Ph.D. diss., Department of American Studies, University of Michigan, Ann Arbor.

Johnson, Colin. 2007. Camp life: The queer history of "manhood" in the civilian conservation corps, 1933-1937. American Studies 48(2): 19-35.

Kandel, William, and John Cromartie. 2004. New patterns of hispanic settlement in rural America. Rural Development Research Report Number 99. Washington, DC: United States Department of Agriculture.

Kazyak, Emily. 2010. The space and place of sexuality: How rural lesbians and gays narrate identity. Ph.D. diss., Department of Sociology. University of Michigan, Ann Arbor, MI.

Kazyak, Emily. 2011a. 'If we were rednecks': The classed meanings of space. Unpublished manuscript. Department of Sociology and Program in Women's \& Gender Studies. University of Nebraska-Lincoln, Lincoln, NE.

Kazyak, Emily. 2011b. 'You'd think the place is full of lesbians!': How gender shapes the experiences of sexual minorities in rural areas. Unpublished manuscript, Department of Sociology and Program in Women's \& Gender Studies. University of Nebraska-Lincoln, Lincoln, NE.

Kennedy, Elizabeth Lapovsky. 1996. 'But we would never talk about it': The structures of lesbian discretion in South Dakota, 1928-1933. In Inventing lesbian cultures in America, ed Ellen Lewin, 15-39. Boston: Beacon Press.

Kennedy, Elizabeth Lapovsky and Madeline Davis. 1993. Boots of leather, slippers of gold: The history of a lesbian community. New York: Penguin Books.

Kirkey, Kenneth, and Ann Forsyth. 2001. Men in the valley: Gay male life on the suburbanrural fringe. Journal of Rural Studies 17(4): 421-41.

Knopp, L. 1997. Gentrification and gay neighborhood formation in New Orleans. In Homo economics: Capitalism, community, and lesbian and gay life, ed. A. Gluckman and B. Reed, 45-59. New York: Routledge.

Levine, Martin. 1998. Gay ghetto. 1979. Reprint. In Social perspectives in lesbian and gaystudies, eds. Peter M. Nardi and Beth E. Schneider, 194-206. New York: Routledge.

Leznoff, Maurice, and William Westley. 1998. The homosexual community. 1956. Reprint. In Social perspectives in lesbian and gay studies, eds. Peter M. Nardi and Beth E. Schneider, 5-11. New York: Routledge.

Lichter, Daniel T., and Kenneth M. Johnson. 2006. Emerging rural settlement patterns and the geographic redistribution of America's new immigrants. Rural Sociology 71(1): 109-31.

Loseke, Donileen R. 2001. Lived realities and formula stories of 'battered women.' In Insti- 
tutional selves: Troubled identities in a postmodern world, eds. Jaber A. Gubrium and James A. Holstein, 107-126. New York: Oxford University Press.

Loseke, Donileen R. 2007. The study of identity as cultural, institutional, organizational, and personal narratives: Theoretical and empirical integrations. The Sociological Quarterly 48: 661-688.

McCarthy, Linda. 2000. Poppies in a wheat field. Journal of Homosexuality 39(1): 75-94.

Moore, Migron R. 2006. Lipstick of timberlands? The meanings of gender presentations in black lesbian communities. Signs: Journal of Women in Culture and Society 32(1): 113-139.

Newton, Esther. 1972. Mother camp: Female impersonators in America. Chicago: University of Chicago Press.

Oswald, Ramona F. 2002. Who Am I in relation to them? Gay, lesbian, and queer people leave the city to attend rural family weddings. Journal of Family Issues 23(3): 323-348.

Oswald, Ramona F., and Linda S. Culton. 2003. Under the rainbow: Rural gay life and its relevance for family providers. Family Relations 52(1): 72-81.

Plummer, Ken. 1995. Telling sexual stories: Power, change, and social worlds. New York: Routledge.

Rosenfeld, Michael J., and Byung-Soo Kim. 2005. The independence of young adults and the rise of interracial and same-sex unions. American Sociological Review 70(4): 541-562.

Rubin, Gayle. 1984. Thinking sex: Notes for a radical theory of the politics of sexuality. In Pleasure and danger: Exploring female sexuality, ed. Carol S. Vance, 267-319. New York: Routledge.

Rubin, Gayle. 1998. The miracle mile: South of market and gay male leather 1962-1997. In Reclaiming San Francisco: History, politics, and culture, eds. James Brooks, Chris Carlsson, and Nancy J. Peters, 247-272. San Francisco: City Lights Books.

Seidman, Steven. 1999. Beyond the closet: The transformation of gay and lesbian life. New York: Routledge.

Somers, Margaret. 1994. The narrative constitution of identity: A relational and network approach. Theory and Society 23(5): 605-649.

Stein, Arlene. 2001. The stranger next door: The story of a small community's battle over sex, faith, and civil rights. Boston: Beacon Press.

United States Department of Agriculture. 2007. Rural definitions. http://www.ers.usda. gov/Data/Ruraldefinitions/

Weston, Kath. 1995. Get thee to a big city: Sexual imaginary and the great gay migration. GLQ: A Journal of Lesbian \& Gay Studies 2(3): 253-277.

$\diamond \diamond \diamond \diamond \diamond \diamond$

Emily Kazyak is Assistant Professor of Sociology and Women's and Gender Studies at the University of Nebraska-Lincoln. Her research interests include sexuality, identity, and the law. Her research has appeared in Gender \& Society and Journal of Family Issues. 